\title{
ISOLAMENTO DE POLÍMEROS DA PAREDE CELULAR DE Saccharomyces cerevisiae E AVALIAÇÃo DA ATIVIDADE ANTIOXIDANTE DA MANANA-PROTEÍNA ISOLADA
}

\author{
Luciana Ferracini-Santos* e Hélia Harumi Sato \\ Departamento de Ciência de Alimentos, Faculdade de Engenharia de Alimentos, Universidade Estadual de Campinas, CP 6121, \\ 13083-862 Campinas - SP, Brasil
}

Recebido em 31/1/08; aceito em 25/8/08; publicado na web em 26/1/09

\begin{abstract}
ISOLATION OF POLYMERS FROM Saccahromyces cerevisiae CELL WALL AND EVALUATION OF ANTIOXIDANT ACTIVITY OF ISOLATED MANNAN-PROTEIN. Yeast cell wall contains polymers glucan and mannan-protein that have received much attention with respect to their biological activities. Conventional isolation process involving treatments with hot alkali and acids cause degradation of these polymers. The aim of this paper was to study a low-degrading process for the isolation of glucan and mannan-protein from S. cerevisiae cell wall comprising physic and enzymatic treatments. Yeast cell glucan was obtained in a purity of $87.4 \%$ and a yield of $33.7 \%$. The isolated mannan-protein presented antioxidant activity that was increased after thirty minutes of protease treatment. Antioxidant activity was determined by $\beta$-carotene/linoleate model system.
\end{abstract}

Keywords: yeast glucan; antioxidant activity; mannan-protein.

\section{INTRODUÇÃO}

A parede celular da levedura Saccharomyces cerevisiae é organizada em duas camadas que são compostas por três macromoléculas principais: manana-proteína, um complexo no qual o polissacarídeo manana está covalentemente ligado à proteína; glucana, um polissacarídeo de $\beta$-1,3 e $\beta$-1,6 glicose e, quitina, um polímero de $\beta-1,4$ $\mathrm{N}$-acetilglicosamina. ${ }^{1-4}$ Estes componentes estão unidos por ligações covalentes. A manana-proteína corresponde a aproximadamente $30 \%$ do peso seco da parede celular, ${ }^{5}$ e compõe a camada mais externa da parede, estando ligada covalentemente a cadeias de $\beta$-1,6-glucana. A $\beta$-1,6-glucana corresponde à cerca de $5 \%$ do peso seco da parede celular e são moléculas relativamente pequenas, com cerca de 140 resíduos de glicose. Mais da metade da parede celular (50-60\%) é formada por $\beta$-1,3-glucana, ${ }^{6}$ que é composta predominantemente por moléculas lineares com cerca de 1500 resíduos de glicose, dos quais cerca de 40 a 50 resíduos estão envolvidos em ligações através do carbono C-6 com moléculas de $\beta$-1,6-glucana e quitina. ${ }^{7}$

A $\beta$-glucana é encontrada também na parede celular de fungos, em cereais como aveia, trigo, centeio, milho, entre outros. ${ }^{8}$ Os estudos sobre a composição das $\beta$-glucanas tiveram grande avanço após a identificação de problemas em filtros utilizados nos processos de produção de cerveja, onde se observou o aparecimento de um material gelatinoso. Este material foi identificado como o polissacarídeo $\beta$-glucana. ${ }^{9}$

As $\beta$-1,3-glucanas apresentam habilidade para estimular o sistema imunológico. ${ }^{5,10}$ Devido a esta função biológica, esse polissacarídeo pode exercer efeito benéfico contra uma série de doenças, como infecções virais, bacterianas e fúngicas, além de tumores, efeitos de radiações e supressão imune devido ao stress. ${ }^{11}$

$\mathrm{O}$ problema que as glucanas apresentam e que inviabiliza sua utilização em alguns casos é sua insolubilidade. Por isso, alguns processos de derivação, como carboximetilação e sulfoetilação, e alguns processos físicos, como tratamento com ultrassom, têm sido propostos com o objetivo de aumentar a solubilidade das glucanas. ${ }^{12}$

As glucanas da levedura Saccharomyces cerevisiae e do fungo

*e-mail: ferracini.luciana@terra.com.br
Aspergillus niger têm sido bastante estudadas. Os processos convencionais para a extração de glucana envolvem tratamentos com álcali e/ou ácido a quente. Estes processos causam a degradação de uma parte da cadeia polimérica, resultando em baixo rendimento e na redução dos efeitos benéficos.

A remoção das proteínas da parede celular e de polissacarídeos álcali solúveis pelo tratamento com hidróxido de sódio ou potássio tem sido considerada eficiente, mas durante este tratamento, os lipídeos da parede celular são hidrolisados em glicerol e ácidos graxos devido à condição alcalina. Foram publicados alguns trabalhos baseados no tratamento da levedura ou da parede celular com $\mathrm{NaOH}$ ou $\mathrm{KOH}$ a quente, preferencialmente em concentrações de 0,75 a 1,0 $\mathrm{M}$ e temperaturas entre 60 e $100{ }^{\circ} \mathrm{C}$, seguido da lavagem com água ou ácido para a remoção da parte solúvel e para a neutralização da mistura, e tratamento com solventes orgânicos para a remoção dos lipídeos, mas o tratamento com álcali ou ácido a quente provocou a degradação da cadeia de glucana. ${ }^{13}$

Freimund et al. ${ }^{13}$ apresentaram um método de isolamento da $\beta$-1,3-glucana de Saccharomyces cerevisiae que consistiu de um processo físico combinado com um tratamento enzimático. $\mathrm{O}$ tratamento físico foi uma extração a quente $\left(125^{\circ} \mathrm{C}\right.$ por $\left.5 \mathrm{~h}\right)$ em solução aquosa de $\mathrm{pH}$ neutro não tamponado, seguido de um tratamento enzimático com a protease comercial Savinase. A pureza da glucana obtida foi de $92 \%$ e o rendimento foi $87 \%$. Este processo de isolamento da glucana gerou um subproduto também benéfico à saúde, a manana-proteína, que é um composto que apresenta algumas atividades biológicas, como atividade antioxidante.

A manana extraída da parede celular de leveduras (Candida utilis, Candida albicans e Saccharomyces cerevisiae) possui atividade antimutagênica e antioxidante, além de apresentar importantes características, como boa solubilidade e massa molecular relativamente pequena (15-30KDa). ${ }^{14,15}$

O objetivo deste trabalho foi estudar o isolamento da glucana da parede celular de Saccharomyces cerevisiae utilizando um processo que combinou tratamento físico e enzimático. Para isso, foi utilizada uma protease alcalina purificada de Cellulosimicrobium cellulans 191, um microrganismo que secreta um complexo enzimático capaz de lisar a parede celular de leveduras. E também estudar o efeito da 
ação desta protease sobre a atividade antioxidante da manana-proteína extraída da parede celular da levedura.

\section{PARTE EXPERIMENTAL}

\section{Material e reagentes}

Foram usados caseína bovina, ácido tricloroacético (99\% de pureza) e clorofórmio para análise química (Merck Co); hexano com pureza para análise química; $\beta$-caroteno ( $98 \%$ de pureza), ácido linoléico (99\% de pureza) e glicose (99\% de pureza - Sigma). A parede celular de Saccharomyces cerevisiae foi extraída mecanicamente em Dyno-Mil (moinho mecânico com pérolas de vidro com diâmetro de 0,02-0,05 mm) e liofilizada, e protease alcalina de Cellulosimicrobium cellulans 191 produzida em meio contendo 8\% de células desidratadas de levedura; $0,2 \mathrm{~g} / \mathrm{L}$ de $\mathrm{MgSO}_{4} .7 \mathrm{H}_{2} \mathrm{O}$ e $2,0 \mathrm{~g} / \mathrm{L}$ de $\left(\mathrm{NH}_{4}\right)_{2} \mathrm{SO}_{4}$ em solução tampão fosfato $0,15 \mathrm{M}$ e pH 8,0 e purificada por meio da precipitação fracionada com sulfato de amônio. Realizou-se cromatografia de troca iônica com resina DEAE-Sepharose e recromatografia com resina Q-Sepharose em FPLC. ${ }^{16}$ A parede celular e a protease foram disponibilizadas pelo Laboratório de Bioquímica da FEA/UNICAMP .

\section{Métodos}

\section{Determinação da atividade de protease}

A mistura de reação contendo $1,5 \mathrm{~mL}$ de solução de caseína $2 \%$, $1 \mathrm{~mL}$ de solução tampão fosfato $0,15 \mathrm{M}(\mathrm{pH} 8,0)$ e $0,5 \mathrm{~mL}$ de solução enzimática foi incubada a $50{ }^{\circ} \mathrm{C}$ por $30 \mathrm{~min}$. A reação foi paralisada pela adição de $3 \mathrm{~mL}$ de solução $0,4 \mathrm{M}$ de ácido tricloroacético (TCA), seguida de filtração em papel Whatman 42. A absorbância do filtrado foi medida a $280 \mathrm{~nm}$, utilizando como controle o meio de reação no qual a solução enzimática foi substituída por solução tampão. ${ }^{17,18}$ Uma unidade de atividade foi considerada a quantidade de enzima necessária para produzir aumento de 1,0 unidade na absorbância do filtrado após 30 min de reação. ${ }^{18}$

\section{Determinação da atividade antioxidante}

A atividade antioxidante foi determinada pela oxidação acoplada do $\beta$-caroteno e do ácido linoléico, de acordo com Hammerschmidt e Pratt, ${ }^{19}$ com algumas modificações. ${ }^{20}$ Foram adicionados $60 \mathrm{mg}$ de ácido linoléico (Sigma Co.), $200 \mathrm{mg}$ de Tween 80 e $5 \mathrm{mg}$ de $\beta$-caroteno (Sigma Co.) em $5 \mathrm{~mL}$ de clorofórmio. Posteriormente, o clorofórmio foi evaporado em evaporador rotatório a $40{ }^{\circ} \mathrm{C}$. O resíduo da evaporação foi dissolvido em $50 \mathrm{~mL}$ de água deionizada e oxigenada sob agitação vigorosa. Alíquotas de $0,5 \mathrm{~mL}$ desta emulsão foram transferidas para tubos de ensaio contendo $0,5 \mathrm{~mL}$ da amostra. A leitura da absorbância foi feita em espectrofotômetro a $470 \mathrm{~nm}$ no tempo inicial e em intervalos de $60 \mathrm{~min}$. A reação de oxidação foi conduzida a $40{ }^{\circ} \mathrm{C}$. Foram utilizados controles que continham água ao invés da amostra. A taxa de branqueamento do $\beta$-caroteno foi determinada pela diferença entre a absorbância inicial e a absorbância final, a $470 \mathrm{~nm}$, dividida pelo tempo de incubação (h). O índice de antioxidação foi calculado pela razão entre a taxa de branqueamento do controle e a taxa de branqueamento da amostra, conforme sugerido por Pratt e Birac. ${ }^{21}$ Todos os testes foram realizados em duplicata.

\section{Determinação de carboidratos totais}

Os polissacarídeos insolúveis da parede celular de $S$. cerevisiae foram submetidos à hidrólise ácida de acordo com a metodologia descrita Dallies et al., ${ }^{22}$ com algumas adaptações. As amostras de $1 \mathrm{mg}$ de glucana em duplicata foram tratadas com $75 \mu \mathrm{L}$ de ácido sulfúrico $72 \%$ (p/p) e deixadas à temperatura ambiente por 3 h. Após este intervalo de tempo, acrescentou-se água destilada e deionizada até o volume final de $1 \mathrm{~mL}$, de forma que a concentração final de ácido sulfúrico foi de $1 \mathrm{M}$. Seguiu-se o tratamento térmico em ebulição por $4 \mathrm{~h}$. Após o resfriamento e a conservação em banho de gelo, o hidrolisado foi diluído com $9 \mathrm{~mL}$ de água destilada e deionizada. Os íons sulfato foram precipitados pela adição de solução saturada de hidróxido de bário até que o pH da solução atingisse a neutralidade. O volume foi ajustado para $25 \mathrm{~mL}$ e o sulfato de bário foi removido por centrifugação a 10.000 x g por 5 min. O sobrenadante foi utilizado como solução de monossacarídeos para as análises de quantificação utilizando-se a metodologia proposta por Dubois et al. ${ }^{23}$

\section{Determinação do conteúdo de proteína}

O conteúdo de proteína foi determinado em duplicata de acordo com a metodologia de Lowry como descrita por Peterson. ${ }^{24}$

Obtenção da parede celular de Saccharomyces cerevisiae extraída mecanicamente

A suspensão de 2,0 kg de levedura comercial em 8,0 L de água destilada, resfriada a $5{ }^{\circ} \mathrm{C}$, foi submetida a tratamento em Dyno Mill utilizando-se fluxo de $80,0 \mathrm{~mL} / \mathrm{min}$ a $2.500 \mathrm{rpm}$ e pérolas de vidro de 0,02-0,05 mm de diâmetro. Após o tratamento, a suspensão de massa celular rompida mecanicamente foi centrifugada a $12.300 \mathrm{x}$ g por 15 min a $5^{\circ} \mathrm{C}$, o precipitado foi lavado com água destilada, até que o sobrenadante permanecesse límpido e, em seguida, foi liofilizado. Os lipídeos foram removidos à temperatura ambiente utilizando-se uma mistura dos solventes hexano e metanol na proporção de 4:1 (v:v) durante $30 \mathrm{~min}^{13}$

\section{Extração da glucana bruta a quente}

A suspensão de $5 \%(\mathrm{~m} / \mathrm{v})$ de parede celular desengordurada em tampão fosfato $50 \mathrm{mM} \mathrm{pH} \mathrm{7,0} \mathrm{foi} \mathrm{tratada} \mathrm{a} 121^{\circ} \mathrm{C}$ por $2 \mathrm{~h} \mathrm{em}$ autoclave (Figura 1). Após o resfriamento, esta suspensão foi centrifugada a $10.000 \mathrm{x}$ g por $15 \mathrm{~min}$ a $5{ }^{\circ} \mathrm{C} .{ }^{25} \mathrm{O}$ precipitado foi lavado duas vezes com a mesma solução tampão, liofilizado e utilizado como glucana bruta para o tratamento enzimático com a protease alcalina. O sobrenadante desta centrifugação foi utilizado para a obtenção da manana-proteína da parede celular.

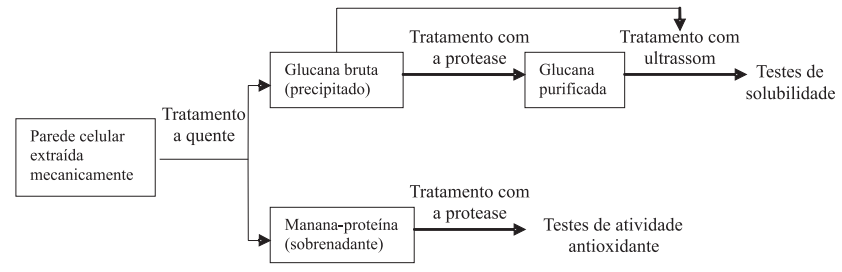

Figura 1. Procedimento para o isolamento dos compostos da parede celular da levedura S. cerevisiae e testes

Tratamento da glucana bruta com a protease alcalina de $C$. cellulans 191

A suspensão de 5\% do liofilizado bruto obtido após a extração a quente (glucana bruta liofilizada) em solução tampão fosfato 50 $\mathrm{mM}$ pH 8,0 e solução enzimática suficiente para que a atividade de protease fosse de $0,5 \mathrm{U} / \mathrm{mL}$ de mistura de reação foi incubada a $50^{\circ} \mathrm{C}$ durante 5 h, com agitação mecânica em intervalos regulares. A reação enzimática foi paralisada pelo aquecimento em banho de ebulição por 10 min. Os resíduos insolúveis foram separados por centrifugação a $10.000 \mathrm{x}$ g por 15 min e lavados duas vezes com água destilada. Para as análises propostas, o sedimento foi desengordurado segundo a metodologia descrita anteriormente. 
Tratamento das glucanas bruta e purificada com ultrassom

O tratamento com ultrassom e a hidratação da glucana foram realizados segundo Mislovicová et al. ${ }^{26}$ com algumas modificações. Utilizou-se uma mistura de $100 \mathrm{mg}$ de glucana (bruta ou purificada) em $25 \mathrm{~mL}$ de água, com pH ajustado para 7,0, e submeteu-se ao tratamento com ultrassom (Unique, mod. USC2850, $120 \mathrm{~W}, 25 \mathrm{KHz}$ ), durante os intervalos de tempo de 15, 30, 60 e $120 \mathrm{~min}$.

Estudou-se também a solubilização com ultrassom das glucanas previamente hidratadas em solução alcalina de $\mathrm{NaOH} 1 \mathrm{M}$ por 24 h. Foram utilizadas as massas 50, 100 e $200 \mathrm{mg}$ de glucana em 25 $\mathrm{mL}$ de meio de hidratação. Após a hidratação, as amostras foram neutralizadas com $\mathrm{HCl}$ concentrado e a suspensão de glucana foi tratada em equipamento de ultrassom durante intervalos de tempo de 10,20 e 30 min a $25^{\circ} \mathrm{C}$.

Após os tratamentos, a glucana insolúvel foi separada por centrifugação a 10.000 x g durante 15 min e determinaram-se os carboidratos totais solúveis no sobrenadante pelo método descrito por Dubois et al.. ${ }^{23}$

\section{Precipitação da manana-proteína com etanol}

Adicionaram-se três volumes de etanol ao sobrenadante para a precipitação da manana-proteína (Figura 1). Após um pernoite a 5 ${ }^{\circ} \mathrm{C}$, o precipitado foi separado por centrifugação a $10.000 \mathrm{x}$ g por 15 min e o solvente foi evaporado. A manana-proteína foi utilizada como substrato para a protease alcalina de C. cellulans 191.

Tratamento da manana-proteína com a protease alcalina de $C$. cellulans 191

O meio de reação contendo $0,5 \%(\mathrm{~m} / \mathrm{v})$ de manana-proteína liofilizada em tampão fosfato $50 \mathrm{mM} \mathrm{pH} \mathrm{8,0} \mathrm{e} \mathrm{protease} \mathrm{alcalina} \mathrm{com}$ atividade de $0,1 \mathrm{U} / \mathrm{mL}$ de meio de reação foi incubado a $50{ }^{\circ} \mathrm{C}$. Em intervalos de tempo de 10, 20, 30, 45, 60, 90, 120 e $180 \mathrm{~min}$, foram retiradas alíquotas para determinação da atividade antioxidante.

\section{RESULTADOS E DISCUSSÃO}

\section{Extração de lipídeos da parede celular de levedura}

A remoção com solvente orgânico à temperatura ambiente foi capaz de extrair lipídeos que corresponderam a 5,3\% da massa inicial da parede celular extraída mecanicamente.

\section{Tratamento a quente para obtenção da glucana bruta}

Freimund et al. ${ }^{13}$ propuseram o tratamento a quente $\left(125^{\circ} \mathrm{C}\right)$ por $5 \mathrm{~h}$ em solução aquosa com $\mathrm{pH}$ neutralizado pela adição de $\mathrm{NaOH}$ para a extração da manana-proteína e Assis ${ }^{25}$ propôs um tratamento a $121^{\circ} \mathrm{C}$ em solução tampão fosfato $50 \mathrm{mM} \mathrm{pH} \mathrm{7,0} \mathrm{durante} 30 \mathrm{~min}$, com a mesma finalidade. No presente trabalho, os dois procedimentos citados foram testados. $\mathrm{O}$ tratamento em solução aquosa provocou degradação maior dos componentes da parede que o tratamento em solução tampão. $\mathrm{O}$ tempo de tratamento de $5 \mathrm{~h}$ foi considerado excessivo.

Este tratamento também teve o objetivo de extrair componentes solubilizáveis da parede celular, principalmente a manana-proteína. Os melhores resultados foram observados quando o tratamento foi realizado em solução tampão fosfato $50 \mathrm{mM} \mathrm{pH} \mathrm{7,0} \mathrm{por} 2 \mathrm{~h}$.

A Tabela1 mostra que o tratamento a quente separou a maior parte da proteína da parede celular. Inicialmente, a parede apresentava $23,2 \%$ de proteína e após este tratamento apresentou $9,4 \%$.

O rendimento de carboidratos totais desta etapa do processo foi de $51 \%$, ou seja, permaneceram insolúveis cerca de $51 \%$ dos carboidratos totais existentes na parede celular antes do tratamento, o restante dos carboidratos foi solubilizado juntamente com a proteína ou foi degradado pelo tratamento. A glucana bruta obtida após o tratamento a quente apresentou $60,6 \%$ de carboidratos totais.

\section{Tratamento da glucana bruta com a protease alcalina de $C$. cellulans 191}

Para a remoção do restante da proteína, que não foi extraída pelo tratamento a quente, fez-se o tratamento enzimático da glucana bruta com a protease alcalina purificada de $C$. cellulans 191 . A degradação excessiva da glucana que é observada nos processos convencionais com tratamento alcalinos ou ácidos pode ser evitada pela introdução deste tratamento enzimático para a remoção da maior parte da proteína da parede.

Os resultados mostraram que a ação enzimática promoveu a remoção de proteína e também de carboidratos (24,4 para 18,3 g). A glucana purificada após o tratamento enzimático apresentou 7,0\% de proteína e $66,7 \%$ de carboidratos totais. O rendimento de glucana purificada após este tratamento foi de 38,2\% (Tabela 1).

A glucana insolúvel obtida após o tratamento enzimático foi desengordurada como descrito anteriormente e utilizada para o estudo da solubilização pelo tratamento com ultrassom.

\section{Tratamento das glucanas bruta e purificada com ultrassom}

O tratamento físico da glucana com ultrassom teve como objetivo aumentar sua solubilização, o que foi avaliado pela determinação de carboidratos totais solúveis antes e depois da exposição ao ultrassom. O estudo foi realizado com a glucana bruta (antes do tratamento com a protease alcalina) e glucana purificada (após o tratamento com a protease alcalina).

Observou-se que o tratamento com ultrassom apresentou baixa eficiência na solubilização da glucana (Tabela 2). Este tratamento foi

Tabela 1. Rendimento e composição da glucana da parede celular de S. cerevisiae durante o processo de isolamento (resultados expressos na forma média \pm desvio padrão; $n=2$ )

\begin{tabular}{|c|c|c|c|c|c|c|}
\hline \multirow{2}{*}{ Fração } & \multirow{2}{*}{$\begin{array}{c}\text { Massa total } \\
(\mathrm{g})\end{array}$} & \multicolumn{2}{|c|}{ Carboidrato total } & \multicolumn{2}{|c|}{ Proteína } & \multirow{2}{*}{$\begin{array}{c}\text { Rend. de glucana } \\
(\%)\end{array}$} \\
\hline & & $(\mathrm{g})$ & $(\%)$ & $(\mathrm{g})$ & $(\%)$ & \\
\hline parede celular desengordurada & $100,0 \pm 0,1$ & $47,9 \pm 1,8$ & 47,9 & $23,2 \pm 1,6$ & 23,2 & 100,0 \\
\hline $\begin{array}{l}\text { glucana bruta após tratamento } \\
\text { a quente }\end{array}$ & $40,3 \pm 1,8$ & $24,4 \pm 1,3$ & 60,6 & $3,6 \pm 0,3$ & 9,4 & 51,0 \\
\hline $\begin{array}{l}\text { glucana purificada após tratamento } \\
\text { enzimático }\end{array}$ & $27,4 \pm 1,0$ & $18,3 \pm 0,4$ & 66,7 & $1,9 \pm 0,3$ & 7,0 & 38,2 \\
\hline $\begin{array}{l}\text { glucana após tratamento } \\
\text { enzimático e desengordurada }\end{array}$ & $18,5 \pm 1,1$ & $16,1 \pm 0,6$ & 87,4 & $1,7 \pm 0,3$ & 9,2 & 33,7 \\
\hline
\end{tabular}


Tabela 2. Porcentagem de carboidratos totais solubilizados pelo tratamento em ultrassom de amostras de glucana da parede celular de $S$. cerevisiae bruta e purificada (resultados expressos na forma média \pm desvio padrão; $\mathrm{n}=2$ )

\begin{tabular}{lcc}
\hline $\begin{array}{l}\text { Tempo de tratamento } \\
(\mathrm{min})\end{array}$ & $\begin{array}{c}\text { Glucana bruta } \\
\text { \% de carboidratos totais solubilizados }\end{array}$ & $\begin{array}{c}\text { Glucana purificada } \\
0\end{array}$ \\
\hline 0,0 & 0,0 \\
15 & 0,0 & $0,2 \pm 0,1$ \\
30 & $0,4 \pm 0,3$ & $0,2 \pm 0,1$ \\
60 & $2,1 \pm 0,6$ & $0,2 \pm 0,1$ \\
120 & $3,3 \pm 0,4$ & $0,3 \pm 0,1$ \\
\hline
\end{tabular}

capaz de solubilizar cerca de dez vezes mais carboidratos da glucana bruta em relação à glucana purificada. Provavelmente esta diferença se deva à remoção de carboidratos observada durante o tratamento enzimático com a protease alcalina.

Para o aumento da solubilidade da glucana, fez-se a sua hidratação prévia como descrito anteriormente. A hidratação em solução $1,0 \mathrm{M}$ de $\mathrm{NaOH}$ antes do tratamento com ultrassom permitiu melhor solubilização da glucana de levedura (Tabela 3) em comparação com a glucana não hidratada apresentada na Tabela 2 .

O tratamento com ultrassom após a hidratação foi capaz de aumentar a solubilização da glucana bruta de 9,9 para $14,7 \%$, quando o tempo de tratamento foi de 30 min e a concentração inicial de glucana foi $200 \mathrm{mg} / 25 \mathrm{~mL}$. O mesmo tratamento para a glucana purificada foi capaz de aumentar a solubilização de 9,7 para $12,4 \%$.

De forma geral, quanto maior o tempo de tratamento com ultrassom, maior a solubilização de carboidratos. As concentrações de 100 e $200 \mathrm{mg} / 25 \mathrm{~mL}$ apresentaram porcentagem de carboidratos solubilizados após o tratamento em ultrassom maior que a concentração de $50 \mathrm{mg} / 25 \mathrm{~mL}$ para a glucana bruta. Mas, o contrário foi observado para a glucana purificada.

A solubilização da glucana bruta foi maior em quase todos os tratamentos quando comparada à glucana purificada. Isso provavelmente se deva ao fato do tratamento enzimático com a protease alcalina ter solubilizado uma parte dos carboidratos da glucana bruta.

Misloviscová et al. ${ }^{26}$ verificaram que o tratamento da glucanaquitina de Aspergillus niger com ultrassom durante $20 \mathrm{~min}$ aumentou a solubilização de carboidratos de 7,6 para 12,2\% quando a concentração inicial foi de $50 \mathrm{mg} / 25 \mathrm{~mL}$. Para a glucana de levedura (Tabela 3) observou-se o aumento na solubilidade de 10,3 para $14,2 \%$ quando a glucana purificada foi submetida a um tratamento idêntico.

\section{Tratamento da manana-proteína com a protease alcalina e avaliação da atividade antioxidante}

O índice de antioxidação da manana-proteína isolada por meio do tratamento a quente foi 1,3; ou seja, a manana-proteína isolada reduziu a oxidação acoplada de $\beta$-caroteno e ácido linoléico em $30 \%$.

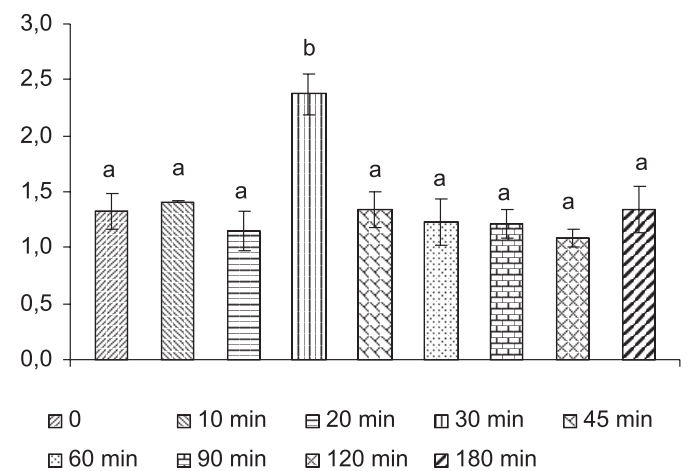

Figura 2. Índice de antioxidação da manana-proteína tratada com a protease alcalina de C. cellulans 191 (Médias seguidas de letras diferentes são estatisticamente diferentes para $p<0,05$ - Teste de Tukey)

Após 30 min de reação com a protease alcalina, o índice de antioxidação da manana-proteína foi aumentado para cerca de 2,4 (Figura 2). A ação da protease gerou compostos, peptídeos ou cadeias de manana-proteína menores, que apresentaram atividade antioxidante maior que a manana-proteína isolada pelo tratamento a quente.

$\mathrm{O}$ tratamento da manana-proteína com a protease alcalina durante 10 e 20 min não promoveu alteração significativa na atividade antioxidante em comparação com a manana-proteína não tratada enzimaticamente. O mesmo ocorreu em períodos de incubação superiores (45-180 min). Observou-se apenas um aumento estatisticamente significativo $(\mathrm{p}<0,05)$ com o tratamento durante $30 \mathrm{~min}$. Este resultado sugere que o aumento na atividade antioxidante foi devido à presença de compostos gerados pela hidrólise parcial de proteínas da parede celular, uma vez que a hidrólise excessiva reduziu o índice de antioxidação a valores próximos do índice da manana-proteína não hidrolisada.

A maior parte dos trabalhos realizados sobre a atividade antioxidante de compostos da parede celular de leveduras estudou a glucana e a manana da parede celular de leveduras..$^{14,15,27-30}$

Jaehrig et al. ${ }^{28}$ verificaram que o potencial antioxidante da parede celular de levedura deve-se menos à glucana que às proteínas da parede celular, especialmente proteínas que apresentam aminoácidos aromáticos ou grupos tiol.

A atividade antioxidante das proteínas e das manana-proteínas da parede celular de leveduras foi menos explorada, e os resultados deste trabalho mostraram que esta atividade pode ainda ser aumentada pela ação da protease alcalina.

\section{CONCLUSÕES}

O polissacarídeo glucana da parede celular de $S$. cerevisiae foi isolado por meio de um procedimento que combina tratamento físico e enzimático com a protease alcalina purificada de Cellulosimicrobium cellulans 191 . Esse processo apresentou $33,7 \%$ de rendimento de glucana com pureza de $87,4 \%$. A hidratação das glucanas bruta e

Tabela 3. Porcentagem de carboidratos totais solubilizados pelo tratamento em ultrassom de amostras de glucana da parede celular de $S$. cerevisiae antes e depois do tratamento enzimático previamente hidratadas

\begin{tabular}{lcccrrccc}
\hline Amostra $(\mathrm{mg} / 25 \mathrm{~mL})$ & \multicolumn{4}{c}{ Glucana bruta } & \multicolumn{4}{c}{ Glucana purificada } \\
\hline Tempo (min) & 0 & 10 & 20 & 30 & 0 & 10 & 20 & 30 \\
50 & $11,6 \pm 1,7$ & $11,8 \pm 0,7$ & - & $11,3 \pm 1,0$ & $10,3 \pm 2,0$ & $10,6 \pm 1,2$ & $14,2 \pm 1,9$ & $14,7 \pm 1,5$ \\
100 & $12,1 \pm 0,8$ & $12,2 \pm 1,1$ & $12,5 \pm 1,3$ & $14,6 \pm 1,5$ & $10,1 \pm 0,6$ & $11,0 \pm 1,3$ & $12,1 \pm 1,1$ & $12,3 \pm 0,8$ \\
200 & $9,9 \pm 2,0$ & $12,0 \pm 1,3$ & $12,9 \pm 0,9$ & $14,7 \pm 1,7$ & $9,7 \pm 1,3$ & $10,7 \pm 9,7$ & $10,5 \pm 0,9$ & $12,4 \pm 1,8$ \\
\hline
\end{tabular}


purificada com $\mathrm{NaOH}$ 1,0M seguida por tratamento com ultrassom aumentou a solubilidade das mesmas.

A protease alcalina de C. cellulans 191 foi capaz de aumentar de 1,3 para 2,4 o índice de atividade antioxidante da manana-proteína isolada da parede celular da levedura após $30 \mathrm{~min}$ de reação, utilizando-se $0,5 \%(\mathrm{~m} / \mathrm{v})$ de manana-proteína e $0,1 \mathrm{U}$ de protease/ $\mathrm{mL}$ de meio de reação.

A partir da parede celular de $S$. cerevisiae é possível obter produtos de alto valor utilizando-se um processo de baixo custo e etapas simples (rompimento mecânico, extração a quente e tratamento com protease). Este processo pode ser de grande interesse para as indústrias de fermentação alcoólica no futuro, pois possibilita a utilização da massa celular de levedura residual do processo de fermentação,

\section{AGRADECIMENTO}

À Capes pelo auxilio recebido.

\section{REFERÊNCIAS}

1. Fleet, G. H.; Curr. Top. Med. Mycol. 1985, 1, 24.

2. Klis, F. M.; Yeast 1994, 10, 851.

3. Andrews, B. A.; Asenjo, J. A.; Biotechnol. Bioeng. 1987, 30, 628.

4. Andrews, B. A.; Asenjo, J. A.; Tibtech. 1987, 5, 273.

5. Lee, J. N.; Lee, D. Y.; Ji, I. H.; Kim, G. E.; Kim, H. N.; Sohn, J.; Kim, S.; Kim, C. W.; Biosci., Biotechnol., Biochem. 2001, 65, 837.

6. Suphantharika, M.; Khunrae, P.; Thanardkit, P.; Verduyn, C.; Bioresour. Technol. 2003, 88, 55.

7. Kaptein, J. C.; Ende, H. V. D.; Klis, F. M.; Biochim. Biophys. Acta 1999, $1426,373$.

8. Genç, H.; Ozdemir, M.; Demirbas, A.; Food Chem. 2001, 73, 221.

9. Vis, R. B. ; Lorenz, K.; LWT-Food Sci. Technol. 1997, 30, 331.

10. Freitas, J. C. O. C.; Medeiros, A. C.; Sales, V. S. F.; Acta Cir. Bras. 2004, $19,296$.
11. Kim, S. K.; Yun, H. S.; Enzyme Microb. Technol. 2005, 39, 496.

12. Sandulá, J.; Kogan, G.; Kacuraková, M.; Machová, E.; Carbohydr. Polym. 1999, 38, 247.

13. Freimund, S.; Sauter, M.; Kapelli, O.; Dutler, H.; Carbohydr. Polym. 2003, 54, 159.

14. Krisková, L.; Duracková, Z.; Sandula, J.; Sasinková, V.; Krajcovic, J.; Mutat. Res., Genet. Toxicol. Environ. Mutagen. 2001, 497, 213.

15. Krizková, L.; Zitnanová, I.; Mislovicavá, D.; Masarová, J.; Sasinková, V.; Duracjová, Z.; Krajcovic, J.; Mutat. Res. 2006, 606, 72.

16. Santos, L. F.; Tese de Doutorado, Universidade Estadual de Campinas, Brasil, 2004.

17. Obata, T.; Iwata, H.; Namba, Y.; Agric. Biol. Chem. 1997, 41, 2387.

18. Rowley, B. I.; Bull, T.; Biotechnol. Bioeng. 1977, 19, 879.

19. Hammerschmidt, P. A., Pratt, D. E.; J.Food Sci. 1978, 43, 556

20. Alencar, S. M.; Tese de Doutorado, Universidade Estadual de Campinas, Brasil, 2002.

21. Pratt, D. E.; Birac, P. M.; J. Food Sci. 1979, 44, 1720.

22. Dallies, N.; François, J.; Paquet, V.; Yeast 1998, 14, 1297.

23. Dubois, M.; Gilles, K. A.; Hamilton, J. K.; Rebers, P. A.; Smith, F.; Anal. Chem. 1956, 28, 350 .

24. Peterson, G.; Anal. Biochem. 1977, 83, 346.

25. Assis, E. M.; Tese de Doutorado, Universidade Estadual de Campinas, Brasil, 1996.

26. Mislovicová, D.; Masárová, J.; Bendzálová, K.; Soltés, L.; Machová, E.; Ultrason. Sonochem. 2000, 7, 63.

27. Jaehrig, S. C.; Rohn, S.; Kroh, L. W.; J. Agric. Food Chem. 2007, 55, 4710.

28. Jaehrig, S. C.; Rohn, S.; Kroh, L. W.; Wildenauer, F. X.; Lisdat, F.; Fleischer, L. G.; Kurz, T.; LWT - Food Sci. Technol. 2008, 41, 868.

29. Bucková, M.; Labuda, J.; Sandula, J.; Krizková, L.; Stepánek, I.; Duracková, Z.; Talanta 2002, 56, 939.

30. Kogan, G.; Stasko, A.; Bauerová, K.; Polovka, M.; Soltes, L.; Brezová, V.; Navarová, J.; Mihalová, D.; Carbohydr. Polym. 2005, 61, 18. 